Received: December 10, 2017

\title{
Research on the Application of Virtual Reality Technology in Landscape Design Teaching*
}

\author{
Zhe $\mathrm{Li}^{1}$ \\ YuNing Cheng ${ }^{2}$ \\ YangYang Yuan ${ }^{3}$ \\ Southeast University \\ Southeast University \\ Southeast University
}

\begin{abstract}
In order to promote the digitization level of landscape design, the application of computer virtual reality technology in landscape teaching is discussed in this paper. Firstly, the probability of related core technology is explained. Secondly, the various stages of virtual reality technology aided landscape design are analyzed, and the SketchUp virtual modelling software is used to explain and demonstrate the specific cases. Finally, the application characteristics and advantages of virtual reality technology are summarized, and the application status of the technology in university landscape architecture education is discussed. The application results show that the introduction of computer virtual technology into the landscape design teaching in universities can effectively improve teaching efficiency, and SketchUp modelling can also complete the virtual modelling of buildings, vegetation and so on to assist landscape design. The research in this paper is of great significance in guiding the application of virtual reality technology in landscape design teaching.
\end{abstract}

\section{Keywords}

Landscape Design • Computer Virtual Technology • Sketchup Modelling • Teaching Application

\footnotetext{
* This research is supported by the National Natural Science Foundation of China (No. 51478104, 51778127)

1 Department of Landscape Architecture, School of Architecture, Southeast University, Nanjing 210096, China. Email: 31757807@qq.com

${ }^{2}$ Correspondence to: Department of Landscape Architecture, School of Architecture, Southeast University, Nanjing 210096, China. Email: yasare@cu.edu.tr

${ }^{3}$ Department of Landscape Architecture, School of Architecture, Southeast University, Nanjing 210096, China. Email: bsabbak@cu.edu.tr
} 
With the advancement of urban modernization and the improvement of people's living standard, the Chinese government is paying more and more attention to the coordinated development of city and environment, and the aesthetic and usage demand of landscape is higher and higher. The design and construction of landscape is in the peak period (Abdulmanan Baharuddin and Chang, 2014). Meanwhile, Landscape Architecture Specialty in universities is generally concerned about the application of virtual technology in teaching, and attaches importance to cultivating students' design and innovation ability through landscape simulation and reproduction. The content of courses is gradually extended to landscape digital analysis and evaluation, landscape virtualization and simulation, etc. Virtual reality technology has achieved initial development in the research and professional practice of Chinese landscape theory, and has also shown great potential for development and application value in landscape architecture teaching.

The virtual reality technology is a simulation and modeling software system applied to landscape design, which is following such three main software as AutoCAD, Photoshop and 3S (RS, GIS and GPS). It is widely used because of its 3I (Interactivity, Immersion and Imagination). It not only greatly reduces the working time and pressure of the designer, but also helps to stimulate the imagination of the designer ( $\mathrm{Xu}$, Kang, Shao and Zhao, 2015). In addition, teachers and students can intuitively understand the design scheme and inspire the design intention from multiple perspectives through the virtual reality technology. Moreover, they can experience the effect of the design as if they were personally on the scene.

The application of computer virtual reality technology in domestic landscape design is not long, and the related research on this technology is still in its infancy. Chinese scholars began to put forward the application of virtual display technology in landscape design in 2004, and in 2008, several articles on the specific application of common virtual reality technologies in landscape planning and design were published by some scholars in the magazine of Chinese Landscape Architecture. However, studies on the system application of virtual reality technology in landscape design is still lacking at present, and there is almost no research on the application of computer virtual technology in landscape design teaching. In addition, the teaching application of this technology is less in the related disciplines of landscape architecture in Chinese colleges and universities, and students are not familiar with the application and actual operation of computer virtual technology at various design stages (Cusimano, 2003).

Taking the above content as the starting point of the research, this paper promotes the application of computer virtual technology in universities' landscape design teaching through introducing the design ideas and practical cases. Firstly, this paper introduces the relevant core concepts and explains the evolution and development process of landscape design. Secondly, the application of virtual reality technology in various stages of landscape design is explained, and the modeling software such as SketchUp is compared with others. Finally, the application examples of computer virtual technology are associated with practical teaching application, which guide college students to use landscape modeling through computer virtual software. The research in this paper has some guiding significance for promoting the application of computer virtual technology in colleges and universities, and at the same time, it can indirectly promote the progress of landscape design. 


\section{Summary about Core Concepts}

\section{The Concept of Landscape}

Landscape is a both ancient and young subject. As an important carrier of human civilization, garden, scenery and landscape have been in existence for thousands of years. As a modern discipline, landscape can be traced back to the end of the 19th century. It is a new discipline paradigm built on the basis of classical gardening and landscape gardening through scientific revolution. Since the establishment of the Landscape Architecture Specialty in Harvard University in 1901, the discipline construction has been developing rapidly throughout the world in more than 100 years. China has decided to divide Landscape Architecture, Architecture and Urban Planning into three parallel disciplines in 2011, which serves the urban construction and city beautification. The modern definition of landscape can be divided into three parts generally: landscape architecture, urban greening and landscape planning (Lavorel et al., 2011).

The education system of Chinese landscape discipline is still in the stage of exploration and development. The unsound discipline system construction, the low level of academic research, not high degree of modern technology application, etc. seriously restrict the development of Chinese landscape discipline (Twidale, 2002). It is imperative to introduce the modern computer technology into the landscape teaching (Xie et al., 2011).

\section{Computer Virtual Reality Technology}

The Concept of Virtual Reality Technology. The so-called virtual reality technology (VR), in fact, refers to the simulation environment generated by all kinds of special devices and computers. When users are placed in the virtual environment, it is as if they were personally on the scene. Therefore, it can be said that the virtual reality technology is actually a kind of technology to realize the natural interaction between human and environment. At present, the virtual reality technology has been applied to entertainment, military, manufacturing, digital museum, architecture design, medical insurance, aerospace special equipment, interior design and other fields (Eastgate et al., 2006).

2.2.2 The 3I Characteristics of Virtual Technology. The virtual reality technology has the 3I characteristics of interaction, immersion and imagination, and the relationship of its characteristics can be displayed by Fig. 1 (Sorkin, Weinshall, Modai and Peled, 2006).

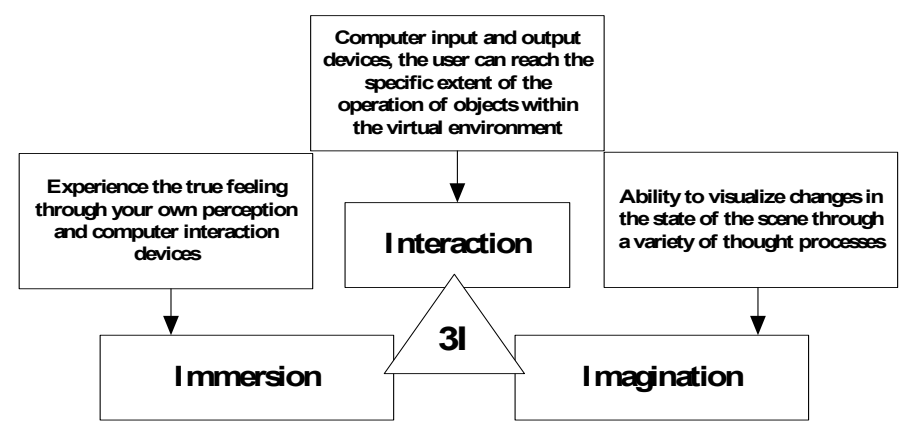

Figure 1. The characteristics of virtual reality 
Based on the triangle features of 3I, the virtual technology allows users to experience the scene of humancomputer interaction and the natural environment simulated by computers. Landscape has always been one of the most pressing areas of virtual reality technology requirements. Virtual reality technology can be widely used in all aspects of landscape research and design, and bring practical help. The virtual reappearance of the landscape design scheme not only gives the user a strong visual impact and obtains a true experience, but also obtains the designed data through its data interface, which is favorable for the design and management personnel to evaluate and optimize the design proposal.

\section{The Evolution and Expression of Landscape Design Thought}

(1) Language and words stage. Language and words are the main forms used to convey the engineering practice and designers' design concept in traditional gardens' design and construction. After thousands of years, many excellent garden projects were built in this way. As far as modern society is concerned, it has become the history of designing and building gardens that simply relying on the design mode of language and words (Weller, R., 2008).

(2) Hand drawing stage. Hand drawing is divided into two types: sketches and formal drawings. Designers express their design inspiration and ideas through sketches, and then on the formal drawings, the ideas are connected by strokes. Hand drawing is the basic skill of landscape architects with unique artistic charm.

(3) Sand table model stage. The sand table shows the designers' inspiration and thinking through the sand table effect, which allows people to look at the effect of the complete landscape within a close range and from multiple perspectives, while assisting designers in correcting the hand-drawn errors (England, J., 1987).

(4) Computer aided design stage. The maturity of computer multimedia technology and computer software technology has promoted the application of computer aided design in landscape. The computer technology can complete landscape design with the highest degree of accuracy, efficiency and revivification, giving users immersive experience (Lyons, W. etc., 2000).

\section{Computer Virtual Reality Technology Assisting Landscape Design}

\section{The Selection of Virtual Reality Modeling Software for Landscape Design}

The currently popular modeling software and their comparison are listed in Tab. 1.

Table 1

Comparison of Five Commonly Used Modeling Software

\begin{tabular}{lcccc}
\hline Software & $\begin{array}{c}\text { Modeling } \\
\text { Speed }\end{array}$ & $\begin{array}{c}\text { Modeling } \\
\text { Ability }\end{array}$ & $\begin{array}{c}\text { Modify the } \\
\text { Convenience }\end{array}$ & $\begin{array}{c}\text { Whether design- } \\
\text { oriented }\end{array}$ \\
\hline 3DS MAX & slow & Strong & Convenient & yes \\
Maya & slow & Very strong & Convenient & yes \\
SketchUp & Very fast & Strong & Very convenient & yes \\
CINEMA4D & fast & Strong & Convenient & no \\
Rhino & fast & Very strong & Convenient & no \\
\hline
\end{tabular}


Since the modeling of landscape design needs design-oriented and convenient software, SketchUp is the first choice for modeling. Besides, SketchUp software has been widely used in landscape design because of its simple operation, strong interaction, online model sharing, rich plug-ins and multiple software interfaces.

\section{The Application and Advantage of Virtual Reality Technology in Various Stages of Landscape Design}

Aiding the Investigation Prior to Project Planning. The preliminary investigation of a project is to confirm the project base, climate, environment, plot ratio, building height, construction cost and time, etc. The feasibility and rationality of the project can be evaluated by using the computer data and information processing technology. Landscape architects can carry out the systematic simulation and preliminary exploration by using VR technology. The VR technology is used to analyze the landscape foundation and evaluate the direction and quality of the landscape. Based on the comprehensive consideration of various factors, the base is divided into different attributes of planning requirements. The application of computer virtual technology in the early stage can connect the design thinking at various stages and promote the continuity of creativity (Pfeiffer, 2010).

Aiding the Project Conceptual Design. Just as designers draw sketches, VR can provide a large number of block models to assist designers in rapid analysis of garden sites. Therefore, designers can effectively master the local relationship and space. Conceptual design is the most critical stage in landscape design, and virtual reality technology can provide indirect help and support to the generation of design concept. The designer is getting closer to his design intuitively in the interactive designing environment by virtual reality technology, and the precise display method makes the designer's design more actual and accurate, easier to succeed (Koh, 2010).

The virtual reality landscape generated by VR technology can eliminate the limitation of two-dimensional sketches. At the beginning of creation, it provides a full view and dynamic perception information for the designer to promote the determination of the scheme. Meanwhile, the rapid visual feedback of the computer enables designers to seize the fleeting inspiration and create new ideas and concepts. The use of virtual reality system is to connect the drawing skills with the structure, with the aid of the expressive force of machine, which gives us the chance to develop design skills and performance skills independently, so that the development of design will not be restricted by relatively low conception development. The digital design of virtual reality technology has provided a new aesthetic view for landscape architecture, and has injected new vitality into the design and modeling.

Aiding the Detailed Design of the Programme. The virtual reality technology can well achieve the breakthrough from two-dimensional thinking mode, namely the "flat cut" mode to the 3D mode, so that designers can freely grasp the space and realize the design scheme more intuitively. VR technology can not only make designers' thinking closer to reality, but also break through the limitation of traditional expression form, and create new design commandments, so as to achieve the poetic pursuit of landscape design. VR technology pays more attention to the multi-dimensional space image of landscape architecture, and embodies more satisfactory means of expression from many aspects such as artistic atmosphere, culture, space, time and society. The virtual reality technology also satisfies the comparison and handover between multiple design 
programmes. By experiencing different images at the same observation point or in different observation sequences, the final plan will eventually be integrated according to the opinions of the designers and experts from multiple plans (Ma, Li and Liu, 2011).

Aiding the Realization of the Programme. On the one hand, the aiding in the realization of the programme refers to the intuition and experience of the owner and common people to the design intention and plan. The technique of VR simulates the actual scene makes audience feel that they are personally on the scene, which can't be achieved with the $2 \mathrm{D}$ effect picture or sandbox.

On the other hand, the aiding in the realization of the scheme is embodied in the scene of landscape construction. VR technology can guide the construction process scientifically and master the whole construction process. Moreover, the computer virtual reality technology can effectively prevent safety accidents, eliminate the security risks, ensure the safety of the project and avoid the waste of construction. At present, there are many large construction projects in China using virtual reality technology, including the design of the new terminal of ZhangYi International Airport and the landscape simulation of Bai-Causeway in West Lake, Hangzhou.

In general, the implementation process of VR technical assistance in landscape design is shown in Fig. 2. Firstly, confirm the design scheme; Secondly, draw the floor plan of the scene with Auto CAD; Thirdly, carry out modeling with SketchUp; Fourthly, adjust the light and material with virtual reality platform, and rendering the whole model; Finally, the executable effect diagrams and animations are generated (Hill and Veitch, 2002).

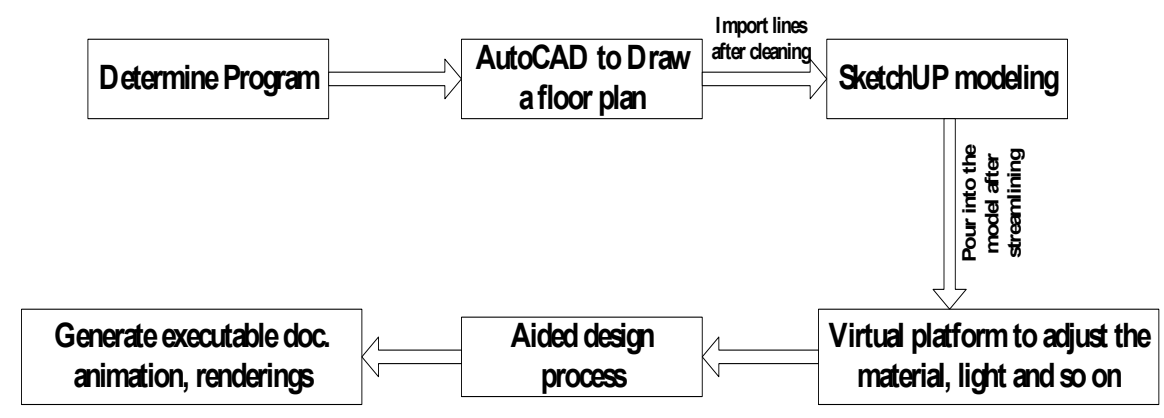

Figure 2. The technical assistance of VR in landscape planning and design implementation process

\section{The Experimental Teaching Case of VR Technology Assisting Landscape Design}

This section will introduce the modeling process by SketchUp software, and enable students of landscape architecture specialty to learn the computer simulation technology intuitively through actual cases, which is also a supplement to the design teaching application.

\section{Overview of Teaching}

Teaching Hardware and Software Environment. Computer configuration: CPU, Intel Core i7, quad core CPU with the basic frequency of $2.6 \mathrm{GHz}$; Video card: dual video card (independent video card + integrated 
graphics card); Hard disk SOOG; Memory: 8GB; 64-bit operating system; Auto CAD two-dimensional drawing software installed; SketchUp 3D modeling software, and so on.

Instructional Objective. The purpose is to allow students to use SketchUp software correctly for practical landscape design. Meanwhile, the goal is to develop students' abilities of study, find and solve problems independently, and to promote students' abilities to design and innovate. It focuses on strengthening students' systematic knowledge structure in the whole process of environmental problem analysis, scientific assessment and judgment, conceptual scheme generation, preliminary scheme discussion and intensification, and achievement expression and verification.

Teaching Steps. First, introduce the name and performance of each tool of SketchUp software, which mainly includes: selection tool, rectangle tool, measuring tool, translation tool, line tool, delete tool and so on.

Second, present and explain the production process, mainly including the making and segmentation of rectangles; The use of stretching, movement and duplication tools to complete the design of the main building structure, landscape site and structure, etc.

Third, produce the external details and supporting facilities of the design structure, complete the design of planting, and adjust the comprehensive effect in the later stage of teaching.

\section{Teaching Case. (1) Building Modeling}

A pavilion in a garden is used as a modeling case to introduce the modeling process. First, draw the base of the pavilion with the rectangle tool, and rectangles of different sizes are drawn, and the height difference between the pavilion and the ground is reflected by the push and pull function.

The optimal modeling in the pavilion is carried out mainly with straight line tool and push and pull tool. First, the bottom position is drawn with straight line tool, and then the whole height is drawn with the push and pull tool.

Path following tool is adopted at the top of the pavilion to form a whole group by rotating, copying, and so on, and then enter SX to get the same type of cornice. Finally, the shape of the pavilion is shown in Fig. 3.

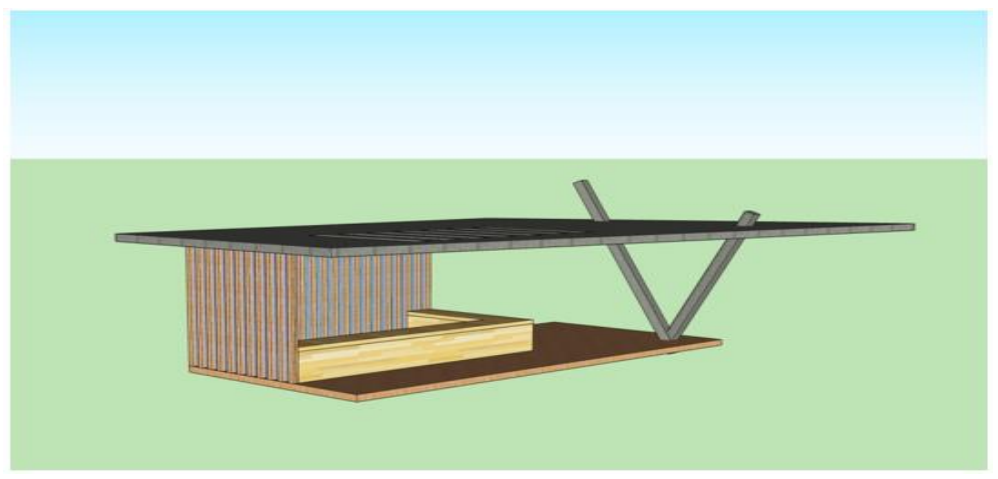

Figure 3. The final shape of the pavilion 


\section{(2) Plant Modeling}

The modeling method of trees has many kinds of expressions according to the complexity, including concept tree model, simple tree model and fine tree model. Figure 4 is a simple tree model that can be built directly from SketchUp.

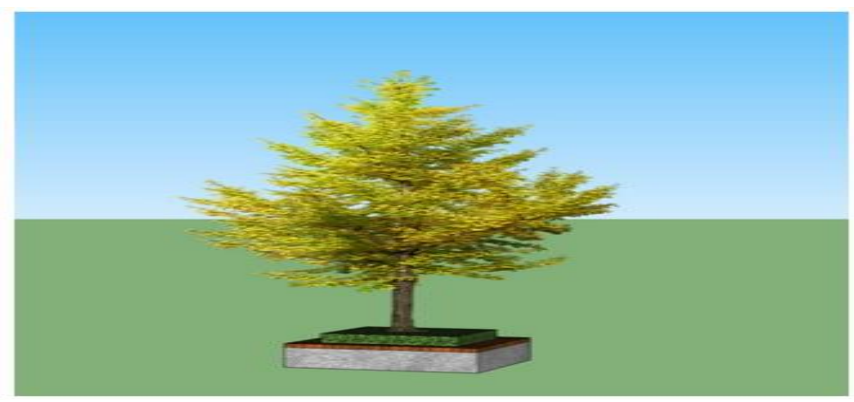

Figure 4. Simple model tree

Figure 5-7 are expression of two-dimensional and three-dimensional plants in landscape designing environment. For trees in the distance, two-dimensional modeling method is adopted, and three-dimensional modeling method is used for nearby trees. On the premise of saving the modeling space, a better expression effect is realized.

Through the experimental teaching cases and under the guidance of teachers, the software operation demonstration and effect display are carried out to students. At the same time, students should be arranged for a long period of hands-on exercise to meet the proficiency requirements of SketchUp software operation.

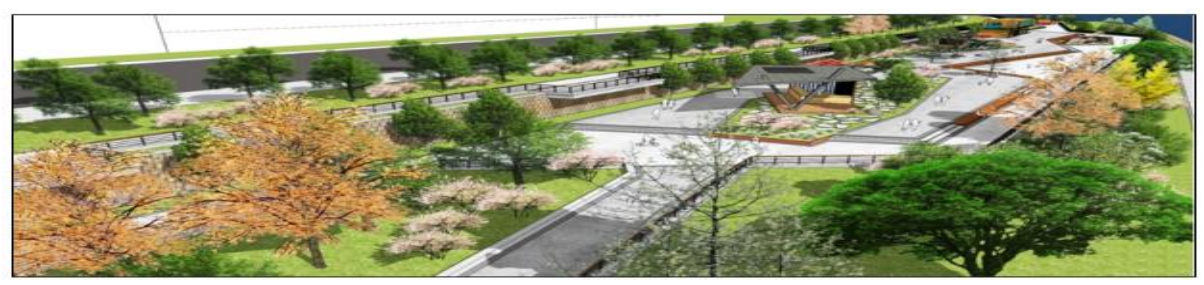

Figure 5. three-dimensional landscape expression (1)

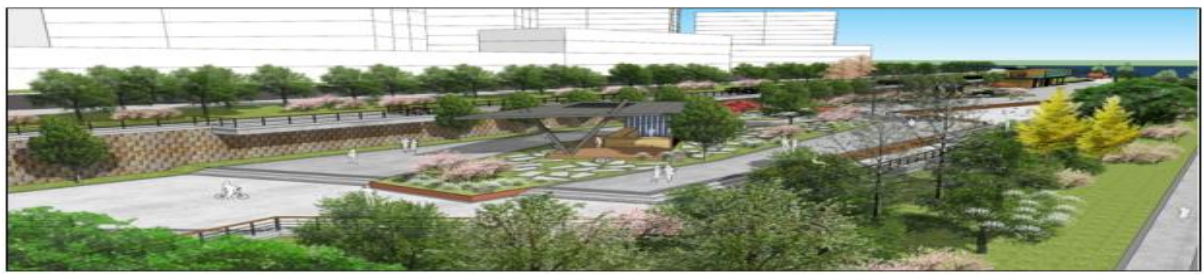

Figure 6. three-dimensional landscape expression (2) 


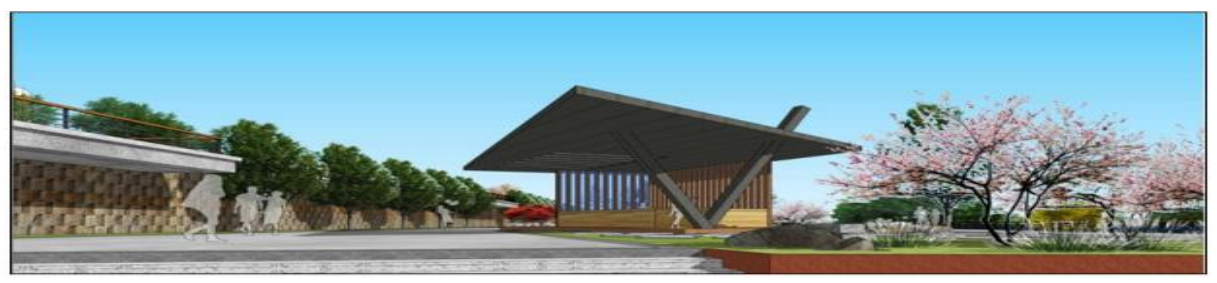

Figure 7. three-dimensional landscape expression (3)

\section{Teaching Prospect}

As an efficient and convenient design tool, computer aided design software is a design method to demonstrate the work in a more effective way. In the course of teaching, teachers should not despise the process of conception and analysis in design work. They shall let students realize that although CAD software is an important auxiliary tool for landscape design, perfect design thinking and design process are the real foundation of ideal landscape design.

At present, there is contradiction between the supply and demand of landscape technicians who have mastered the computer virtual reality technology. A large number of talents with corresponding skills are expected to be cultivated by universities. The research shows that the 3I characteristics of computer aided instruction technology can well assist designers in completing the work from the early stage of investigation to the later stage of construction. Therefore, it is an inevitable tendency for colleges and universities to popularize the operation teaching of related computer virtual reality technology among students of landscape architecture specialty.

\section{Conclusion}

This paper introduces the development track and background of landscape design, and clarifies the demand for the application of computer aided VR technology in the industry. Then, the characteristics of computer virtual reality technology and its application scope and advantages in various stages of landscape design are introduced. The modeling steps of SketchUp are introduced through actual teaching cases. At the same time, the application effect is demonstrated. The main content and significance of this study are as follows:

(1) The application status and advantages of computer virtual reality technology in landscape design are popularized, which is beneficial to the popularization of the technology in landscape teaching.

(2) The specific modeling steps and effects of SketchUp modeling technology are demonstrated from such two aspects as architecture and vegetation, which is conducive to guiding the landscape planning and design teaching in colleges and universities. 


\section{References}

Abdulmanan, A. F. N., Baharuddin, A., \& Chang, L. W. (2014). A detailed survey of the palm and biodiesel industry landscape in Malaysia. Energy, 76(1), 931-941. http://dx.doi. org/10.1016/j.energy.2014.09.007.

Cusimano, M. D. (2003). Virtual reality surgery: Neurosurgery and the contemporary landscape a threedimensional interactive virtual dissection model to simulate transpetrous surgical avenues. Neurosurgery, 53(4), 1010. http://dx.doi. org/10.1227/01.neu.0000086144. 44927.e3.

Eastgate, R. M., Griffiths, G. D., Waddingham, P. E., Moody, A. D., Butler, T. K. H., \& Cobb, S. V., et al. (2006). Modified virtual reality technology for treatment of amblyopia. Eye, 20(3), 370. http://dx.doi. org/10.1038/sj.eye.6701882.

England, J. (1987). Glaciation and the evolution of the canadian high arctic landscape. Geology, 15(5), 419424.

Koh, J. (2010). Design research integration in landscape architecture, a wageningen experience. Journal of Applied Physiology, 106(1), 29-39.

Lavorel, S., Grigulis, K., Lamarque, P., Colace, M. P., Garden, D., \& Girel, J., et al. (2011). Using plant functional traits to understand the landscape distribution of multiple ecosystem services. Journal of Ecology, 99(1), 135-147. http://dx.doi. org/10.1111/j.1365-2745.2010.01753. x.

Lyons, W., Fountain, R., dagger, Doran, P., Dagger, and Priscu, J. C., et al. (2000). Importance of landscape position and legacy: the evolution of the lakes in taylor valley, antarctica. Freshwater Biology, 43(3), 355367. http://dx.doi. org/10.1046/j.1365-2427.2000.00513. x.

Ma, J., Li, G., \& Liu, H. (2011). The application of investigation teaching method in class instruction of landscape architecture. IEEE, 2474-2476. http://dx.doi. org/10.1109/ aimsec.2011.6011059.

Pfeiffer, M. (2010). Photovoltaics in open space design-integration of technological equipment as challenge for landscape architecture. Synapse, 68(11), 518-528.

R. A. Hill, \& N. Veitch. (2002). Cover. landscape visualization: rendering a virtual reality simulation from airborne laser altimetry and multi-spectral scanning data. International Journal of Remote Sensing, 23(17), 3307-3309. http://dx.doi. org/10.1080/01431160110119731.

Sorkin, A., Weinshall, D., Modai, I., \& Peled, A. (2006). Improving the accuracy of the diagnosis of schizophrenia by means of virtual reality. American Journal of Psychiatry, 163(3), 512. http://dx.doi. org/10.1176/appi.ajp.163.3.512.

Twidale, C. R. (2002). The two-stage concept of landform and landscape development involving etching: origin, development and implications of an idea. Earth-Science Reviews, 57(1-2), 37-74. http://dx.doi. org/10.1016/s0012-8252(01)00059-9.

Weller, R. (2008). Transects - 100 years of landscape architecture and regional planning at the school of design of the university of pennsylvania. Pathology, 40(40), 313-314.

Xie, X., Wang, Q., Dai, L., Su, D., Wang, X., \& Qi, G. (2011). Application of china's national forest continuous inventory database. Environmental Management, 48(6), 1095. http://dx.doi. org/10.1007/s00267-011-97162. 
Xu, J., Kang, J., Shao, L., \& Zhao, T. (2015). System dynamic modelling of industrial growth and landscape ecology in china. Journal of Environmental Management, 161, 92. http://dx.doi. org/10.1016/j.jenvman.2015.06.026. 